\section{PARASITOS INTESTINAIS EM CRIANÇAS MENORES DE 5 ANOS, RESIDENTES NO RECIFE.}

\section{José Maurício Alves Camello}

Realizamos exames de fezes em 1500 crianças de ambos os sexos, menores de 5 anos, residentes no Recife. As fezes foram trazidas, aleatoriamente, ao Laboratório de Parasitologia da Universidade Federal do Pernambuco. Evitamos a duplicidade de exames para uma mesma criança. Quando o material fecal estava moldado, usamos os métodos de Hoffman,
Pons e Janer e Rugai e colaboradores. Em fezes pastosas ou diarréicas, realizamos, também, o método direto para pesquisa de trofozoítos. Examinamos 3 aliquotas do sedimento fecal, após coloração pelo lugol.

Para diferenciação das larvas de ancilostomideos e de Strongyloides stercoralis usamos a chave de classificação proposta por Amato Neto e Correa (Exame Parasitológico das fezes 4a Ed. Sarrier. São Paulo, 1980).

A idade e o sexo das crianças examinadas constam da Tabela 1.

Tabela 1 - Relação dos examinados e sua distribuição por idade e sexo.

\begin{tabular}{lrr}
\hline Sexo & $<1$ & 1 \\
\hline Masculino & 36 & 202 \\
Feminino & 33 & 137 \\
\hline Total & 69 & 339 \\
\hline Os resultados para protozoários foram os se- \\
guintes: \\
Giardia lamblia & & \\
Chilomastix mesnili & 276 & $71,13 \%$ \\
Entamoeba coli & 15 & $3,86 \%$ \\
Entamoeba histolytica & 37 & $9,54 \%$ \\
Iodameba bütschlii & 10 & $2,58 \%$ \\
Endolimax nana & 5 & $1,29 \%$ \\
& 45 & $11,29 \%$
\end{tabular}
seguinte:

Quanto aos helmintos a positividade foi a

\section{Ascaris lumbricoides}

Trichuris trichiura

Ancylostomidae (Ancilostomideos)
$39148,27 \%$

$37245,93 \%$

$232,84 \%$

\title{
2
}

3

4

Total

\begin{tabular}{cccc}
179 & 152 & 181 & 750 \\
160 & 228 & 192 & 750 \\
\hline 339 & 380 & 373 & 1500 \\
\hline
\end{tabular}

$\begin{array}{lll}\text { Strongyloides stercoralis } & 9 & 1,11 \% \\ \text { Enterobius vermiculares } & 8 & 0,99 \% \\ \text { Hymenolepis nana } & 7 & 0,86 \%\end{array}$

Tabela 2 - Parasitos detectados em amostras fecais das crianças examinadas segundo a idade

\begin{tabular}{|c|c|c|c|c|c|c|c|c|c|c|c|c|}
\hline Parasi- & $\begin{array}{l}\text { Giardia } \\
\text { lamblia }\end{array}$ & $\begin{array}{c}\text { Enta- } \\
\text { moeba } \\
\text { coli }\end{array}$ & $\begin{array}{c}\text { Enta- } \\
\text { moeba } \\
\text { histolytica }\end{array}$ & $\begin{array}{c}\text { Ioda- } \\
\text { moeba } \\
\text { butschlii }\end{array}$ & $\begin{array}{l}\text { Endo- } \\
\text { limax } \\
\text { nana }\end{array}$ & $\begin{array}{l}\text { Chilo- } \\
\text { mastix } \\
\text { mesnili }\end{array}$ & $\begin{array}{l}\text { Ascaris } \\
\text { lumbri- } \\
\text { coides }\end{array}$ & $\begin{array}{l}\text { Trichuris } \\
\text { trichiura }\end{array}$ & $\begin{array}{l}\text { Ancilos- } \\
\text { tomideos }\end{array}$ & $\begin{array}{c}\text { Strongy- } \\
\text { loides ster- } \\
\text { coralis }\end{array}$ & $\begin{array}{c}\text { Enterobius } \\
\text { bius ver- } \\
\text { micularis }\end{array}$ & $\begin{array}{l}\text { Hymeno- } \\
\text { lepis } \\
\text { nana }\end{array}$ \\
\hline$<1$ & 34 & 2 & 0 & 0 & 2 & 3 & 41 & 15 & 0 & 0 & 0 & 0 \\
\hline 1 & 116 & 5 & 2 & 0 & 8 & 8 & 142 & 109 & 8 & 2 & 6 & 3 \\
\hline 2 & 54 & 6 & 0 & 3 & 9 & 1 & 85 & 94 & 5 & 3 & 2 & 1 \\
\hline 3 & 38 & 15 & 5 & 0 & 18 & 0 & 62 & 80 & 5 & 4 & 0 & 3 \\
\hline 4 & 34 & 9 & 3 & 2 & 8 & 3 & 61 & 74 & 5 & 0 & 0 & 0 \\
\hline Total & 276 & 37 & 10 & 5 & 45 & 15 & 391 & 372 & 23 & 9 & 8 & 7 \\
\hline
\end{tabular}

